\title{
Correlation between the Clinical Profile and Angiographic Severity of Coronary Artery Disease in ST Elevation Myocardial Infarction and Non-ST Elevation Myocardial Infarction Patients
}

\author{
$\begin{array}{lll}\text { C. Rohit Swaminathan } & \text { P. Arun Prasath } \\ & \end{array}$ \\ ${ }^{1}$ Department of General Medicine, Mahatma Gandhi Medical College \\ and Research Institute, Pondicherry, India \\ 2 Department of Cardiology, Mahatma Gandhi Medical College and \\ Research Institute, Pondicherry, India
}

Ind J Car Dis Wom 2021;6:145-154.

\begin{abstract}
Address for correspondence Dr. Arun Prasath (MD, DM-Cardiology), Associate Professor, Department of Cardiology, Mahatma Gandhi Medical College and Research Institute, Puducherry, India (e-mail: arunprasath80@gmail.com).
\end{abstract}

\begin{abstract}
Keywords

- Acute coronary syndrome

- SYNTAX score

- clinical profile

- angiographic severity.

Background and Aim: The correlation between clinical profile and angiographic severity in acute coronary syndrome (ACS) patients has been poorly documented. Hence, the present study aimed to study the clinical profile and correlate that with vessel burden, as witnessed by coronary angiography, in patients presenting to the hospital with ACS (ST-segment elevation myocardial infarction [STEMI]/non-ST-segment elevation [NSTE]-ACS)

Materials and Methods: The study had enrolled 209 patients who had been diagnosed with ACS. All subjects were those who presented to the Emergency Medicine Department in a tertiary care center (south India). Coronary angiogram done for these patients by cardiologists was reviewed with a SYNTAX CALCULATOR (I AND II). Patient's baseline characteristics and clinical examination and interventional diagnosis details were obtained.

Results: The clinical profile gathered from this geographical territory implied an increase in the angiographic severity of the coronary artery disease as measured by the SYNTAX score 1, with an increase in the duration of the said risk factor. Male gender was predominant and the major age group for ACS was 30 to 60 years. The most common presentation in ACS was STEMI. Diabetes and hypertension were the main risk factors for ACS. There was a striking occurrence of ACS among the young.

Conclusion: STEMI was the major ACS presentation in this study population. The main risk factors noted were diabetes and hypertension. Besides smoking and alcohol abuse (in any study population), dyslipidemia was also a key risk factor observed. Mild left ventricular systolic dysfunction was predominant in this study. The SYNTAX score 1 increased with duration of observed and recorded risk factors.
\end{abstract}

DOI https://doi.org/ $10.1055 / \mathrm{s}-0041-1736251$. ISSN 2455-7854.
(C) 2021. Women in Cardiology and Related Sciences. All rights reserved.

This is an open access article published by Thieme under the terms of the Creative Commons Attribution-NonDerivative-NonCommercial-License, permitting copying and reproduction so long as the original work is given appropriate credit. Contents may not be used for commercial purposes, or adapted, remixed, transformed or built upon. (https://creativecommons.org/ licenses/by-nc-nd/4.0/)

Thieme Medical and Scientific Publishers Pvt. Ltd., A-12, 2nd Floor, Sector 2, Noida-201301 UP, India 


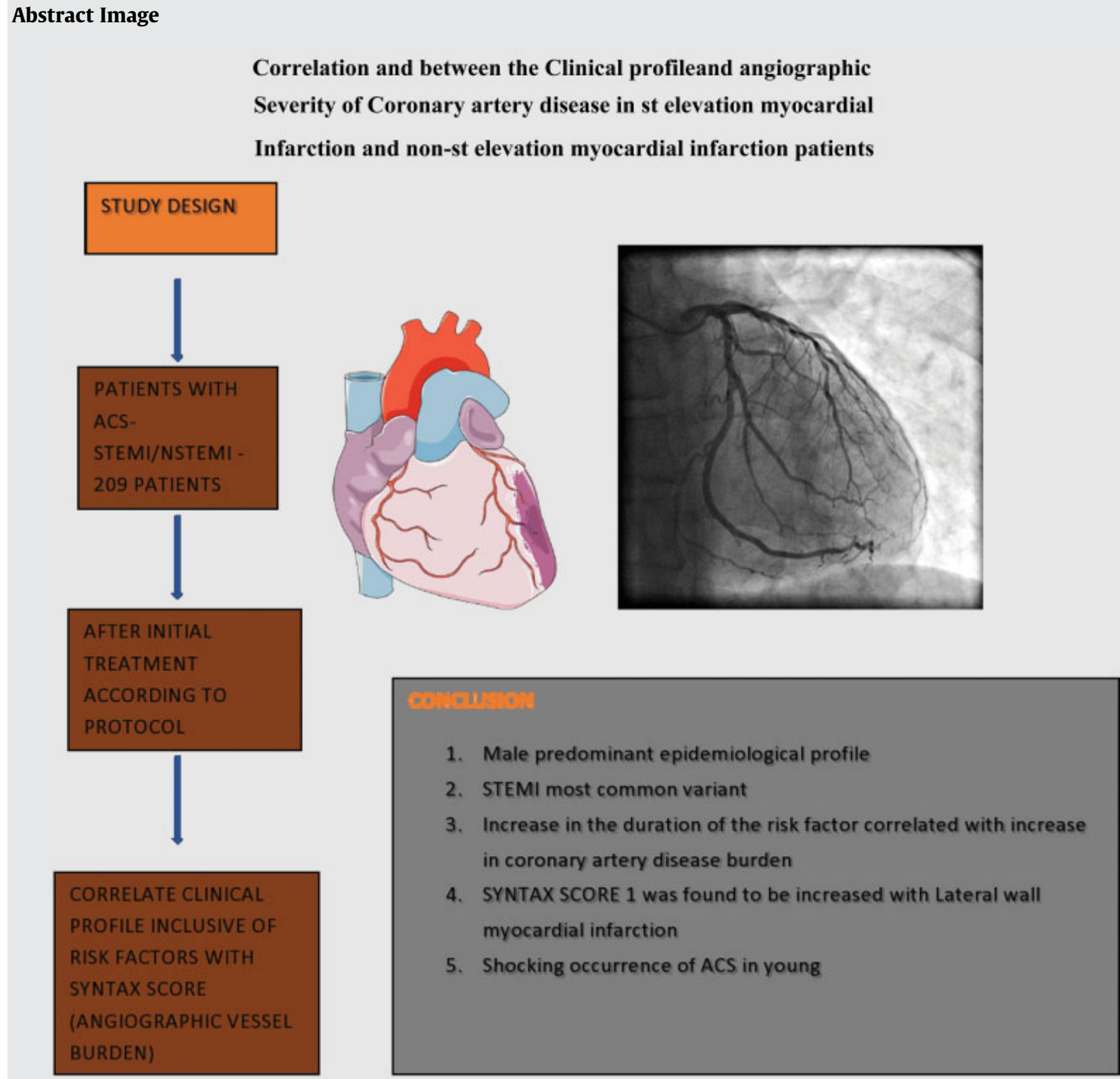

\section{Introduction}

The primary cause of death in the world is cardiovascular disease (CVD), which is responsible for 17.5 million deaths per year. In many developed countries, coronary heart disease mortality is declining, but in developing and transitional countries, it is increasing, partly as a result of increasing ageing, urbanization, and lifestyle changes. ${ }^{1}$

Acute coronary syndrome (ACS) is a concept that describes a sudden decrease in coronary blood flow, resulting from an acute ischemic insult to the myocardium. The ECG results will help to identify patients into two main divisions, with significant diagnostic and therapeutic implications ${ }^{2}$. ACS with STsegment elevation normally describes an acute complete coronary occlusion and presents with acute chest pain and recurrent elevation of $>1 \mathrm{~mm}$ ST-segment in at least two anatomically contiguous leads. This condition is referred to as acute ST-segment elevation myocardial infarction (STEMI). Immediate reperfusion with primary angioplasty or fibrinolytic therapy is the mainstay of treatment in these patients. ${ }^{3}$ Although biomarkers are useful for confirmatory and prognostic purposes, they are not mandatory and should not interrupt care when diagnosing STEMI.

Patients with acute chest pain but no recurrent elevation of the ST-segment are referred to as acute non-ST-segment elevation ACS (NSTE-ACS). The ECG may be normal or there may be intermittent elevation of the ST-segment, persistent or transient depression of the ST-segment, inversion of $\mathrm{T}$ waves, flat $\mathrm{T}$ waves, or pseudonormalization of $\mathrm{T}$ waves.

In order to select an effective management approach, physicians may need to stratify patients according to their risk status and according to the original risk evaluation. Serial 
ECGs and cardiac biomarkers are included in the initial risk assessment. ${ }^{4}$ The percutaneous coronary intervention synergy (SYNTAX) score is a systematic method of angiographic scoring. ${ }^{5}$ It directs the decision-making process between surgery for coronary artery bypass graft (CABG) and percutaneous coronary intervention (PCI).

This calculator takes into consideration the dominance of coronary circulation, total occlusion, trifurcation, calcification, tortuosity of a particular lesion, length of the lesion, and the thrombus content of the lesion.

There are few published studies on the clinical profile of coronary artery disease (CAD) in patients with ACS and its angiographic severity. The purpose of this research, therefore, was to correlate the clinical profile and angiographic significance of CAD in patients with ACS.

\section{Methodology}

This was a cross-sectional study done with universal sampling. A total of 209 consecutive patients presenting to a tertiary care hospital, between January 2019 to June 2020, with their first episode of ACS were analyzed. This was approved by the Institutional Human Ethics Committee. Written informed consent was obtained from the patients. The clinical presentations of patient were categorized as unstable angina (UA), non-ST-segment elevated myocardial infarction (NSTEMI) and STEMI, according to American College of Cardiology/American Heart Association (ACC/AHA) definitions and treated as per ACC/AHA recommendations. ${ }^{6}$

For the study, the following data were included:

1. Age.

2. Gender.

3. CAD risk factor profile-

A) Current history of cigarette/bidi smoking.

B) Alcohol intake.

4. Dyslipidemia was identified as the presence of either of the following: patients on lipid-lowering drugs or total cholesterol $(\mathrm{TC})>240 \mathrm{mg} / \mathrm{dl}$, triglycerides $(\mathrm{TG})>150$ $\mathrm{mg} / \mathrm{dl}$, low-density lipoprotein (LDL) $>130 \mathrm{mg} / \mathrm{dl}$, and high-density lipoproteins (HDL) $<50 \mathrm{mg} / \mathrm{dl}$ for female and $<40 \mathrm{mg} / \mathrm{dl}$ for male

5. Diabetes mellitus was defined by the plasma glucose concentration $\geq 200 \mathrm{mg} / \mathrm{dl}(11.1 \mathrm{mmol} / \mathrm{L})$, fasting blood sugar $\geq$ $126 \mathrm{mg} / \mathrm{dl}$ ( $7.0 \mathrm{mmol} / \mathrm{L})$, or $2-\mathrm{hp} \geq 200 \mathrm{mg} / \mathrm{dl}(11.1 \mathrm{mmol} / \mathrm{L})$.

6. Systemic hypertension (systolic blood pressure $\geq 140$ and/or diastolic $\geq 90 \mathrm{~mm} \mathrm{Hg}$ and/or on antihypertensive treatment) was taken into account.

7. Family history of CAD (first-degree relatives before the age of 55 years in men and 65 years in women).

8. Records of clinical signs, left ventricular ejection fraction (LVEF), hematological indices, coronary angiographic results, and treatment strategy were collected and extensively reviewed. LVEF was classified into normal (>60\%), borderline normal (50-60\%), mild (40-50\%), moderate (30-40\%), and severe $(<30 \%)$.

The clinical profile was gathered with the objectives in mind. Patients were subsequently subjected to coronary angi- ography and their atherosclerotic burden was calculated using the SYNTAX score calculator. SYNTAX score 1 depicts the angiographic vessel severity. SYNTAX score II was calculated to decide on the management of the disease (PCI/CABG). SYNTAX score II incorporated the SYNTAX score 1 along with ejection fraction, sex of the patient, glomerular filtration rate, angiographic evidence of involvement of the left main coronary artery, history or clinical evidence of chronic obstructive pulmonary disorder (COPD), and history or clinical evidence of peripheral vascular disease. All patients enrolled were subjected to analysis .This study correlated the demographic profile of the local or presenting population with the angiographic severity of coronary vasculature.

After the coronary angiography, the patients were categorized on basis of the number of vessels involved and the severity of the lesion. Revascularization plan was formulated on the basis of the achieved data (PCI/CABG).

The results were reported as mean \pm standard deviation for the quantitative variables and percentages for the categorical variables. All the statistical analyses were carried out via Statistical Package for Social Sciences version 20 (SPSS, IL, Chicago Inc., USA).

\section{Results}

STUDY DESIGN: OBSERVATIONAL CROSS SECTIONAL STUDY

The individuals who participated in this study belonged to a single group. The group consisted of individuals belonging to STEMI and NSTEMI.

A total of 209 patients were included in the final analysis.

Table 1 Descriptive analysis of gender distribution in study population

\begin{tabular}{|l|l|l|}
\hline Gender & Frequency & Percentage \\
\hline MALE & 172 & 82.3 \\
\hline FEMALE & 37 & 17.7 \\
\hline TOTAL & 209 & 100.0 \\
\hline
\end{tabular}

Among the 209 patients who were included in the study, it was found out that $82.3 \%$ (172 participants) were male and $17.7 \%$ (37 participants) were female.

Table 2 Descriptive analysis of echocardiographic findings

\begin{tabular}{|l|l|l|}
\hline Echo & Frequency & Percent \\
\hline Normal LV function ( $>60 \%)$ & 59 & 28.2 \\
\hline Adequate LV function (50-60\%) & 47 & 22.5 \\
\hline $\begin{array}{l}\text { Mild LV systolic dysfunction } \\
(40-50 \%)\end{array}$ & 71 & 34.0 \\
\hline $\begin{array}{l}\text { Moderate LV systolic dysfunction } \\
(30-40 \%)\end{array}$ & 30 & 14.4 \\
\hline $\begin{array}{l}\text { Severe LV systolic dysfunction } \\
(<30 \%)\end{array}$ & 2 & 1.0 \\
\hline Total & 209 & 100.0 \\
\hline
\end{tabular}


Among the 209 ACS patients who were studied, 59 patients had normal left ventricular systolic function. About 47 patients had adequate left ventricular systolic function. Predominantly, patients presenting with ACS had mild left ventricular systolic dysfunction. In this population, 71 patients had mild left ventricular systolic dysfunction, and 30 patients had moderate left ventricular systolic dysfunction. Only 2 patients in our study had severe left ventricular systolic dysfunction.

Table 3 Descriptive analysis of distribution of smoking as a risk factor in the study population

\begin{tabular}{|l|l|l|}
\hline Smoking & Frequency & Percent \\
\hline Nonsmoker & 141 & 67.5 \\
\hline Less than 5 years & 5 & 2.4 \\
\hline 5-10 years & 22 & 10.5 \\
\hline $10-20$ years & 28 & 13.4 \\
\hline More than 20 years & 13 & 6.2 \\
\hline Total & 209 & 100.0 \\
\hline
\end{tabular}

In this study population, there were 141 patients who were nonsmokers and 68 patients who were smokers. More than 13 patients were smokers for more than 20 years.

Table 4 Distribution of patients with alcohol abuse

\begin{tabular}{|l|l|l|}
\hline Alcoholism & Frequency & Percent \\
\hline Nonalcoholic & 137 & 65.6 \\
\hline Less than 5 years & 19 & 9.1 \\
\hline 5-10 years & 31 & 14.8 \\
\hline $10-20$ years & 18 & 8.6 \\
\hline More than 20 years & 4 & 1.9 \\
\hline Total & 209 & 100.0 \\
\hline
\end{tabular}

In this study population, 137 patients were nonalcoholics and 53 patients had history of alcohol abuse. Four patients had alcohol abuse for more than 20 years.

Table 5 Distribution of diabetics in the study population

\begin{tabular}{|l|l|l|}
\hline Diabetes & Frequency & Percent \\
\hline Nondiabetic & 98 & 46.9 \\
\hline Less than 5 years & 62 & 29.7 \\
\hline $5-10$ years & 29 & 13.9 \\
\hline $10-20$ years & 15 & 7.2 \\
\hline More than 20 years & 5 & 2.4 \\
\hline Total & 209 & 100.0 \\
\hline
\end{tabular}

In this study population, 121 patients were diabetics. This data makes type 2 diabetes mellitus the most common risk factor in this study population. Predominantly, these patients were diabetics for less than 5 years.

Table 6 Distribution of patients with systemic hypertension as a risk factor

\begin{tabular}{|l|l|l|}
\hline Systemic hypertension & Frequency & Percent \\
\hline Nonhypertensive & 116 & 55.5 \\
\hline Less than 5 years & 74 & 35.4 \\
\hline $5-10$ years & 15 & 7.2 \\
\hline $10-20$ years & 4 & 1.9 \\
\hline Total & 209 & 100.0 \\
\hline
\end{tabular}

In this study population, 93 patients were hypertensives. Predominantly, patients were hypertensives for less than 5 years.

Table 7 Distribution of patients with dyslipidemia in the study population

\begin{tabular}{|l|l|l|}
\hline Dyslipidemia & Frequency & Percent \\
\hline Nondyslipidemic & 182 & 87.09 \\
\hline Dyslipidemic & 27 & 12.91 \\
\hline Total & 208 & 100.0 \\
\hline
\end{tabular}

About 27 patients were dyslipidemic in our study.

Table 8 Distribution of acute coronary event according to age group

\begin{tabular}{|l|l|l|}
\hline Age & Frequency & Percent \\
\hline$<30$ years & 5 & 2.4 \\
\hline $30-60$ years & 146 & 69.9 \\
\hline$>60$ years & 58 & 27.8 \\
\hline
\end{tabular}

The most common age group of disease occurrence in our study was between the ages of 30 to 60 years. A total of 146 patients belonged to this group. More than 50 patients belonged to the age group of more than 60 years.

Table 9 Distribution of type of ACS among the study populations

\begin{tabular}{|l|l|l|}
\hline Diagnosis & Frequency & Percent \\
\hline AWMI & 71 & 34.0 \\
\hline IWMI & 46 & 22.0 \\
\hline UA & 46 & 22.0 \\
\hline NSTEMI & 29 & 13.9 \\
\hline LWMI & 2 & 1.0 \\
\hline IWMI with extension & 15 & 7.2 \\
\hline Total & 209 & 100.0 \\
\hline
\end{tabular}

Abbreviations: ACS, acute coronary syndrome; AWMI, anterior wall myocardial infarction; IWMI, inferior wall myocardial infarction; LWMI, lateral wall myocardial infarction NSTEMI, non-ST-segment myocardial infarction; UA, unstable angina. 
In our study, a striking predominance of anterior wall STEMI was noticed. The second most common type of acute coronary event was inferior wall STEMI and ACS-UA.

Table 10 Distribution of type of ACS among the study populations

\begin{tabular}{|l|l|l|}
\hline ACS & Frequency & Percent \\
\hline STEMI & 134 & 64.1 \\
\hline NSTEMI & 75 & 35.9 \\
\hline
\end{tabular}

Abbreviations: ACS, acute coronary syndrome; NSTEMI, non-ST-segment myocardial infarction; STEMI, ST-segment myocardial infarction.

The most common type of acute coronary event, according to the broad classification was the STEMI variant, with 134 patients suffering from this ailment.

Table 11 Correlation between SYNTAX score and diagnosis

\begin{tabular}{|l|l|l|l|l|}
\hline SS1 & $\begin{array}{l}\text { Number } \\
\text { of } \\
\text { patients }\end{array}$ & $\begin{array}{l}\text { Median } \\
\text { SS1 }\end{array}$ & $\begin{array}{l}\text { IQR } \\
(25 \text { th-75th) }\end{array}$ & $\begin{array}{l}p \text {-Value } \\
\text { (Kruskal- } \\
\text { Wallis) }\end{array}$ \\
\hline AWMI & 71 & 12.000 & $(7-17)$ & \\
\hline IWMI & 46 & 10.500 & $(5.375-15.000)$ & 0.060 \\
\hline UA & 46 & 7.000 & $(1.500-16.875)$ & \\
\hline NSTEMI & 29 & 17.000 & $(7.500-24.000)$ & \\
\hline LWMI & 2 & 20.500 & $(16.000)$ & \\
\hline $\begin{array}{l}\text { IWMI with } \\
\text { extension }\end{array}$ & 15 & 12.000 & $(2.000-17.000)$ & \\
\hline
\end{tabular}

Abbreviations: ACS, acute coronary syndrome; AWMI, anterior wall myocardial infarction; IQR, interquartile range; IWMI, inferior wall myocardial infarction; LWMI, lateral wall myocardial infarction NSTEMI, non-ST-segment myocardial infarction; UA, unstable angina.

SYNTAX score 1 was found to be higher in patients presenting with lateral wall MI.

Table 12 Correlation between ACS according to broad classification and SYNTAX score

\begin{tabular}{|l|l|l|l|l|}
\hline $\begin{array}{l}\text { Type of } \\
\text { ACS }\end{array}$ & $\boldsymbol{n}$ & $\begin{array}{l}\text { Median } \\
\text { SS1 }\end{array}$ & IQR (25th-75th) & $\begin{array}{l}\text { p-Value } \\
\text { (Mann- } \\
\text { Whitney) }\end{array}$ \\
\hline STEMI & 134 & 11.500 & $(5.000-17.000)$ & 0.926 \\
\hline NSTEMI & 65 & 10.000 & $(4.000-22.000)$ & \\
\hline
\end{tabular}

Abbreviations: ACS, acute coronary syndrome; IQR, interquartile range; NSTEMI, non-ST-segment myocardial infarction; STEMI, ST-segment myocardial infarction.

As our data had a non-normal distribution, we applied a nonparametric test (Kruskal-Wallis) to the data. In the correlation between the type of ACS and angiographic severity (SYNTAX score 1), the median value in this study for patients with STEMI was 11.500 and NSTEMI was 10.500 . This value was found to be higher in the STEMI group. However, this did not correlate statistically.
Table 13 Correlation between SYNTAX score and smoking

\begin{tabular}{|l|l|l|l|l|}
\hline Comorbidity & $\begin{array}{l}\text { Number of } \\
\text { patients }\end{array}$ & $\begin{array}{l}\text { Median } \\
\text { SS1 }\end{array}$ & IQR (25th-75th) & $\begin{array}{l}p \text {-Value } \\
\text { (Kruskal- } \\
\text { Wallis) }\end{array}$ \\
\hline Nonsmoker & 141 & 10.000 & $(4.000-17.500)$ & 0.463 \\
\hline$<5$ years & 5 & 9.000 & $(1.000-15.750)$ & \\
\hline $5-10$ years & 22 & 12.500 & $(5.750-17.625)$ & \\
\hline $10-20$ years & 28 & 10.000 & $(3.750-23.125)$ & \\
\hline$>20$ years & 13 & 15.000 & $(7.500-22.0000$ & \\
\hline
\end{tabular}

As our data had a non-normal distribution, we applied a nonparametric test (Kruskal-Wallis ) to the data. In the correlation between duration of smoking and SYNTAX score 1 , there was an increase in median value with increase in duration of smoking.

Table 14 Correlation between alcohol use and SYNTAX score

\begin{tabular}{|l|l|l|l|l|}
\hline Comorbidity & $\begin{array}{l}\text { Number of } \\
\text { patients }\end{array}$ & $\begin{array}{l}\text { Median } \\
\text { SS1 }\end{array}$ & IQR (25th-75th) & $\begin{array}{l}p \text {-Value } \\
\text { (Kruskal- } \\
\text { Wallis) }\end{array}$ \\
\hline Nonalcoholic & 137 & 10.000 & $(5.000-18.000)$ & 0.043 \\
\hline$<5$ years & 19 & 7.000 & $(0.000-14.500)$ & \\
\hline $5-10$ years & 31 & 10.000 & $(4.000-18.000)$ & \\
\hline $10-20$ years & 18 & 16.500 & $(10.250-28.625)$ & \\
\hline$>20$ years & 4 & 14.500 & $(9.250-65.000)$ & \\
\hline
\end{tabular}

As our data had a non-normal distribution, we applied a nonparametric test (Kruskal-Wallis) to the data. In the correlation between duration of alcohol abuse and angiographic severity of CAD (SYNTAX score), we noticed an increase in median value with increase in duration of alcohol use. The maximum median values were found in the duration time frame of 10 to 20 years. This was also statistically significant.

Table 15 Correlation between duration of hypertension and syntax score

\begin{tabular}{|l|l|l|l|l|}
\hline Comorbidity & $\begin{array}{l}\text { Number } \\
\text { of } \\
\text { patients }\end{array}$ & $\begin{array}{l}\text { Median } \\
\text { SS1 }\end{array}$ & IQR (25th-75th) & $\begin{array}{l}p \text {-Value } \\
\text { (Kruskal- } \\
\text { Wallis) }\end{array}$ \\
\hline Nonhypertensive & 116 & 8.000 & $(3.000-17.000)$ & 0.034 \\
\hline$<5$ years & 74 & 10.500 & $(5.000-19.250)$ & \\
\hline $5-10$ years & 15 & 15.000 & $(9.000-25.500)$ & \\
\hline $10-20$ years & 4 & 13.000 & $(10.250-17.250)$ & \\
\hline
\end{tabular}

As our data had a non-normal distribution, we applied a nonparametric test (Kruskal-Wallis) to the data. In the correlation between duration of systemic hypertension and angiographic severity by SYNTAX score 1 , we observed an increase in the median SYNTAX score as the duration of systemic hypertension progressed, with maximum median values in the time frame of 5 to 10 years. This was also statistically significant. 
Table 16 Correlation between duration of diabetes and SYNTAX score

\begin{tabular}{|l|l|l|l|l|}
\hline Comorbidity & $\begin{array}{l}\text { Number } \\
\text { of } \\
\text { patients }\end{array}$ & $\begin{array}{l}\text { Median } \\
\text { SS1 }\end{array}$ & IQR (25th-75th) & $\begin{array}{l}\text { p-Value } \\
\text { (Kruskal- } \\
\text { Wallis) }\end{array}$ \\
\hline Nondiabetic & 98 & 8.500 & $(2.000-18.000)$ & 0.098 \\
\hline$<5$ years & 62 & 10.000 & $(6.750-15.625)$ & \\
\hline $5-10$ years & 29 & 13.500 & $(5.500-22.750)$ & \\
\hline $10-20$ years & 15 & 15.000 & $(10.000-25.000)$ & \\
\hline$>20$ years & 5 & 14.000 & $(5.500-27.500)$ & \\
\hline
\end{tabular}

As our data had a non-normal distribution, we applied a nonparametric test (Kruskal-Wallis) to the data. In the correlation between duration of diabetes and angiographic severity by SYNTAX score 1 , we observed an increase in the median SYNTAX score as the duration of diabetes progressed, with maximum median values in the time frame of 10 to 20 years.

Table 17 Correlation between Killip and SYNTAX score

\begin{tabular}{|l|l|l|l|l|}
\hline Killip & $\begin{array}{l}\text { Number } \\
\text { of } \\
\text { patients }\end{array}$ & $\begin{array}{l}\text { Median } \\
\text { SS1 }\end{array}$ & $\begin{array}{l}\text { IQR } \\
\text { (25th-75th) }\end{array}$ & $\begin{array}{l}\text {-Value } \\
\text { (Kruskal- } \\
\text { Wallis) }\end{array}$ \\
\hline Normal & 179 & 10.000 & $(4.000-16.500)$ & 0.056 \\
\hline CREPTS present & 16 & 15.000 & $(8.250-25.375)$ & \\
\hline Pulmonary edema & 4 & 18.750 & $(4.500-31.875)$ & \\
\hline Cardiogenic shock & 10 & 17.500 & $(8.750-25.250)$ & \\
\hline
\end{tabular}

As our data had a non-normal distribution, we applied a nonparametric test (Kruskal-Wallis) to the data. In the correlation between Killip classification and angiographic severity by SYNTAX score 1 , we observed an increase in the median SYNTAX score as the Killip class progressed, with maximum median values in Killip-3 (pulmonary edema). This was also statistically significant.

Table 18 Correlation between left ventricular dysfunction and SYNTAX score

\begin{tabular}{|l|l|l|l|l|}
\hline EF & N & $\begin{array}{l}\text { Median } \\
\text { SS1 }\end{array}$ & IQR (25th-75th) & $\begin{array}{l}\text { p-Value } \\
\text { (Kruskal- } \\
\text { Wallis) }\end{array}$ \\
\hline Normal LV function & 59 & 9.000 & $(3.000-23.500)$ & 0.339 \\
\hline $\begin{array}{l}\text { Adequate LV } \\
\text { function }\end{array}$ & 47 & 8.000 & $(2.000-17.000)$ & \\
\hline $\begin{array}{l}\text { Mild LV systolic } \\
\text { dysfunction }\end{array}$ & 71 & 13.000 & $(7.000-17.000)$ & \\
\hline $\begin{array}{l}\text { Moderate LV } \\
\text { systolic dysfunction }\end{array}$ & 30 & 11.000 & $(7.000-19.875)$ & \\
\hline $\begin{array}{l}\text { Severe LV systolic } \\
\text { dysfunction }\end{array}$ & 2 & 11.500 & $(3.500)$ & \\
\hline
\end{tabular}

Abbreviations: $E F$, ejection fraction; IQR, interquartile range; LV, left ventricle.

As our data had a non-normal distribution, we applied a nonparametric test (Kruskal-Wallis) to the data. In the correlation between EF and angiographic severity by SYNTAX score 1 , we noticed maximum median values in patients with mild LVEF (EF 40-50\%).

\section{Subgroup Analysis in Female Study Population}

We also did a subgroup analysis in the female study population which included 37 patients.

Table 19 Diabetes in the female population

\begin{tabular}{|l|l|l|}
\hline Diabetes & Frequency & Percent \\
\hline Nondiabetic & 12 & 32.4 \\
\hline Less than 5 years & 13 & 35.1 \\
\hline $5-10$ years & 6 & 13.5 \\
\hline $10-20$ years & 6 & 13.5 \\
\hline more than 20 years & 2 & 5.4 \\
\hline Total & 37 & 100.0 \\
\hline
\end{tabular}

A study across the number and the duration of diabetes mellitus among the female population, again, proved that the trend with respect to the number of years the participant suffered from it were less than 5 years mattered. A total of 13 patients had diabetes for less than 5 years.

Table 20 Systemic hypertension in the female population

\begin{tabular}{|l|l|l|}
\hline Systemic hypertension & Frequency & Percent \\
\hline Nonhypertensive & 18 & 48.6 \\
\hline Less than 5 years & 14 & 37.8 \\
\hline $5-10$ years & 3 & 8.1 \\
\hline $10-20$ years & 2 & 5.4 \\
\hline Total & 37 & 100.0 \\
\hline
\end{tabular}

Here again, 14 patients out of 37 patients were hypertensives for less than 5 years.

Table 21 Distribution of type of ACS among the female population

\begin{tabular}{|l|l|l|}
\hline Diagnosis & Frequency & Percent \\
\hline AWMI & 7 & 18.9 \\
\hline IWMI & 9 & 24.3 \\
\hline UA & 13 & 35.1 \\
\hline NSTEMI & 3 & 8.1 \\
\hline LWMI & 0 & 0 \\
\hline IWMI with extension & 5 & 13.5 \\
\hline Total & 37 & 100.0 \\
\hline
\end{tabular}

Abbreviations: ACS, acute coronary syndrome; AWMI, anterior wall myocardial infarction; IWMI, inferior wall myocardial infarction; LWMI, lateral wall myocardial infarction NSTEMI, non-ST-segment myocardial infarction; UA, unstable angina. 
UA, in contrast, was the most common acute coronary event.

Table 22 Age category

\begin{tabular}{|l|l|l|}
\hline Age & Frequency & Percent \\
\hline $30-60$ years & 26 & 70.3 \\
\hline$>60$ years & 11 & 29.7 \\
\hline
\end{tabular}

Table 23 Type of acute coronary event in female population

\begin{tabular}{|l|l|l|}
\hline Acute coronary syndrome & Frequency & Percent \\
\hline STEMI & 21 & 56.8 \\
\hline NSTEMI & 16 & 43.2 \\
\hline
\end{tabular}

Abbreviations: ACS, acute coronary syndrome; NSTEMI, non-ST-segment myocardial infarction; STEMI, ST-segment myocardial infarction.

But, collectively 21 patients presented to us with STEMI, making this the most common broader classified acute coronary event.

Table 24 Correlation between diabetes mellitus and SYNTAX score 1 in women

\begin{tabular}{|l|l|l|l|l|}
\hline Comorbidity & $\begin{array}{l}\text { Number } \\
\text { of } \\
\text { patients }\end{array}$ & $\begin{array}{l}\text { Median } \\
\text { SS1 }\end{array}$ & IQR (25th-75th) & $\begin{array}{l}\text { p-Value } \\
\text { (Kruskal- } \\
\text { Wallis) }\end{array}$ \\
\hline Nondiabetic & 12 & 6.000 & $(0.500-13.750)$ & 0.557 \\
\hline$<5$ years & 13 & 8.000 & $(0.000-15.750)$ & \\
\hline $5-10$ years & 5 & 11.00 & $(6.500-18.250)$ & \\
\hline $10-20$ years & 5 & 15.000 & $(5.500-28.000)$ & \\
\hline$>20$ years & 2 & 11.000 & $(8.500-)$ & \\
\hline
\end{tabular}

We noticed an increase in the SYNTAX score 1 with respect to increase in the duration of diabetes, with the maximum syntax score observed close to 10 to 20 years of the comorbidity. But this was not statistically significant.

Table 25 Correlation between systemic hypertension and syntax score 1 in women

\begin{tabular}{|l|l|l|l|l|}
\hline Comorbidity & $\begin{array}{l}\text { Number } \\
\text { of } \\
\text { patients }\end{array}$ & $\begin{array}{l}\text { Median } \\
\text { SS1 }\end{array}$ & IQR (25th-75th) & $\begin{array}{l}p \text {-Value } \\
\text { (Kruskal- } \\
\text { Wallis) }\end{array}$ \\
\hline Nonhypertensive & 18 & 6.000 & $(0.000-14.250)$ & .261 \\
\hline$<5$ years & 14 & 12.500 & $(2.750-18.875)$ & \\
\hline $5-10$ years & 3 & 14.000 & $(11.000-)$ & \\
\hline $10-20$ years & 2 & 10.500 & $(10.000-)$ & \\
\hline
\end{tabular}

The above dictum was also noticed in the female population, with the maximum SYNTAX score being observed over the duration of hypertension (5-10 years), and only three patients in the category, although not statistically significant.

\section{Discussion}

Among the patient profile that were collected, clear trends regarding the demographic profile of the presenting population could be established. This demographic profile could also be correlated with the vessel burden, using SYNTAX score 1 , where majority of it had statistical significance. We also noticed an increase in the severity of the CAD with increase in duration of the risk factor.

\section{Age and Sex}

In this study, $82.3 \%$ of the patients were males and $17.7 \%$ were females (-Table $\mathbf{1}$ ). This exhibits a striking male predominance in acute coronary events. We also observed in this study which covered all age groups, not restricting ourselves to a particular set, that most of the patients fell under the age group of 30 to 60 years. Comparing it with the published literature, this was confirmed.

Prajapathi et al did a single center, observational study in novel risk factors and angiographic profile in patients presenting with ACS. They had found that males presented with ACS 24 times more than females in the age group under 40 years and 8 times more than females in the age group more than 40 years. They had also confirmed maximum number of cases presented in the age group of 30 to 60 years. Adding to this, the most common type and subvariant of acute coronary event was anterior wall MI (AWMI). ${ }^{7}$

\section{Echocardiographic Analysis}

In this study, $34 \%$ of patients had mild left ventricular systolic dysfunction, followed by normal left ventricular systolic function (28.2\%) (-Table 2). This was strikingly confirmed by literature worldwide.

In a prospective cohort study done by Brezinov et al in Israel, where a total of 8983 patients who were diagnosed with ACS were admitted (2000-2010) in various critical care units across the country. Among the patients enrolled, 4470 patients had mild-to-moderate left ventricular systolic dysfunction and 3659 patients had preserved LVEF. Less than $10 \%$ of patients had severe left ventricular dysfunction. ${ }^{8}$

\section{Smoking and Alcoholism}

It is clear and evident that smoking and alcohol abuse is an important risk factor for CAD and even more important in deciding the mortality risk and the vessel burden. In our study, although, the nonsmoker population was about $67.5 \%$. The maximum number of smokers in this study had practiced the habit for 5 to 10 years ( - Table 3 ). In contrast to some journals published, this was not the most common risk factor in this study pertaining to this geographical area.

A study done in Sweden by Bjork et al comprised 93,416 patients who presented with acute MI (AMI). These patients were collected from the Register of Information and Knowledge about Swedish Heart Intensive Care Admissions. In this observational entry, $38 \%$ patients had STEMI and $62 \%$ patients 
had NSTEMI. Among smokers, 31\% patients presented with STEMI and $22.9 \%$ presented with NSTEMI. In this article, among men with STEMI, $58 \%$ of the youngest, that is, less than 50 years were smokers, whereas in men with NSTEMI, $47 \%$ of them were smokers. In contrast to this, among young women presenting with STEMI, $67 \%$ of them were smokers ${ }^{9}$

Interestingly, smoker's paradox was recorded by Katayama et al in a study of 528 patients who were admitted with diagnosis of AMI; $44 \%$ of the case load were smokers. But the paradox was that the 6-month mortality was lower in the smokers than the non-smokers. The earlier ST resolution was also higher in smokers. Most of the smokers in this study were males ${ }^{10}$

In our study, $65.5 \%$ were nonalcoholics (-Table 4). Most of the patients were exposed to alcohol/had the habit of consuming alcohol occasionally. Binge drinking pattern was also noticed among the study population. The data on heavy binge prior to the MI is not available. Comparing this to world literature, a case control study was performed across 52 countries by Leong et al. The INTERHEART study was done with 12,461 individuals who presented with AMI. This study provided valuable information on alcohol use as a risk factor and its demographic characteristics. For instance, in women less than 45 years, it was found it had a protective effect. They also assessed whether a heavy binge preceding the event of ACS has a correlation. The hazard period to binge was defined as alcohol consumption within 24 hours prior to the event. Control period was defined as 48 hours prior to the event during which the binge took place. It was found that heavy binge ( $>6$ drinks) during hazard period significantly increases risk of MI. The more harmful association of occurrence of $\mathrm{MI}$ in those who drank more frequently was also established. Hence binge drinking, especially in older individuals, led to MI. Moderate amount consumption in most populations had a lower risk of MI. This however could not be said for all geographical variables. It was also stipulated that binge drinking could have brought in acute but drastic changes in the lipid profile. It could also result in overt hypertension 20 hours after the binge. ${ }^{11}$

\section{Type II Diabetes and Systemic Hypertension}

These two risk factors are established as direct causative risk factors in MI, increasing cardiovascular burden, and secondary pathological diagnosis. In this study, diabetes was the most common risk factor (53.1\%) (-Table 5). The bulk of the patients were recently diagnosed or were victims of the condition for less than 5 years. Systemic hypertension was found in about $44.5 \%$ of patients. Again, here too, the bulk of the patients were recently diagnosed hypertensives $(<5$ years) ( - Table 6 )

Correlating this with the global literature, Isezuo et al achieved a cross-sectional retrospective study of 1468 patients who presented with ACS. This study was done in Madras Medical Mission, Chennai, India. These patients were followed-up for a year after hospitalization. Systemic hypertension, type II diabetes mellitus, and dyslipidemia were found to be top risk factors ${ }^{12}$ ( - Table 7 ).

\section{Correlation between Clinical Profile and Syntax Score}

There were some characteristic findings in this study, some of which had statistical significance.

Correlation between the type of event (STEMI/NSTE-ACS) and SYNTAX score 1 was done. It was found that the STEMI variant had a slightly higher median value of 11.500 than the NSTEMI variant, which had a median value of 10.000 . But the range of quartiles was much higher in the NSTEMI group (-Table 12).

Correlation between the duration of smoking and SYNTAX score 1 was observed. Here, the duration of smoking more than 20 years had the highest median value of 15 (-Table 13).

Correlation between the duration of alcohol consumption/exposure was noted. Here, too, as the duration of exposure rose, the median value of SYNTAX score 1 increased. Median value of 16.500 was observed, which was the highest and found in the duration of 10 to 20 years (-Table 14).

As explained earlier, as in any massive literature entry or miniscule study, diabetes mellitus and systemic hypertension are the most important risk factors. In this study, it was noted that a median value of 15.000 was present, and it was highest in patients with a history of diabetes duration of 10 to 20 years. This was also found in patients who had systemic hypertension as a risk factor. Here, too, a median value of 15.000 was observed. The median value of SYNTAX score 1 was highest in patients with history of systemic hypertension for 10 to 20 years. So, the duration of risk factor implied an increase in the SYNTAX score (-Table 15).

Only 24 patients were diabetics. But in the diabetic population, high SYNTAX score was noted in 10 patients, whereas 14 others had low and mid scores. This implies that diabetics have a more severe angiographic burden (-Table 16). As predicted, high SYNTAX score also meant high mortality risk. ${ }^{13}$

Killip III/IV had the maximum median values of 18.750 and 17.500 , respectively. This depicted increase in SYNTAX score as the Killip presentation increased. ${ }^{17}$

Looking at global literature, a study was done by Choudhary et al in SMS Hospital (Jaipur), where SYNTAX score 1 was calculated for 90 patients presenting with STEMI and for those who were planned for PCI. SYNTAX score was broadly classified into low, mid, and high. Low being $<15$, mid being 16 to 22 and high being $>23$. In this study, the mean age was $54.2 \pm 11.6$. There was male predominance as stated before. In this study, tobacco usage was the major risk factor, followed closely by systemic hypertension and diabetes mellitus. A total of 49 patients were smokers, of which 17 fell under low and mid, and 15 had high SYNTAX score. A total of 39 patients were hypertensives. 15 had low score, 12 had mid score, and 12 other patients had high scores.

In our study, AWMI was the most common, and lateral wall MI was the least common, with 71 patients suffering from the former and 2 patients from the latter (-Table 11). 
A study done by Tanveer et al, Sri Jayadeva Institute of Cardiovascular Science and Research, Bangalore, confirmed this data. This registry studied the correlation between SYNTAX score in STEMI and high-sensitivity C-reactive protein (CRP). This study also took into account the clinical profile which makes this study unique. Males were more commonly affected. Mean age was $54.37 \pm 11.73$. Dyslipidemia was the most common risk factor in this study, with 158 patients having deranged lipid profile, which makes this study unique as either smoking or diabetes have been recorded in every other study. In this, patients were divided into the following three groups based on SYNTAX score: low (0-22), intermediate (23-31) and high (> 33). Most patients belonged to the low category. ${ }^{14}$

In another study done by Dursun et al, 348 patients with MI were identified. A total of 161 were diagnosed to have STEMI and the rest NSTEMI. NSTEMI patients were found to be more commonly smokers, diabetics, and had a strong prior ischemic heart disease. In this study, SYNTAX score was found to be higher in the STEMI group ${ }^{15}$.

Finally, the most important risk factor, deranged lipid profile, which was not the most common risk factor in this population. Only 27 patients were found to have dyslipidemia (-Table 7). In this study, we have correlated LDL and non-HDL with SYNTAX score 1, hoping for a significance, but there was none. A study done by Kurmus et al in Turkey did a retrospective study which involved 574 patients requiring coronary angiography, but published no statistical correlation between LDL/non-HDL and SYNTAX score $1 .{ }^{16}$ In another study published by Li et al, from Wuhan University, 1867 patients were evaluated and analyzed retrospectively. SYNTAX score 1 in this population also were divided into three groups-mild $(<8)$, moderate $(8-15)$ and severe $(>15)$. NonHDL in this study was found to be higher in the mild group. ${ }^{17}$

\section{Conclusion}

Our study showed a male predominance in the study population that presented. Type II diabetes mellitus and systemic hypertension were the two most common risk factors. The occurrence of ACS in patients who had duration of the above said two risk factors for less than 5 years was also noticed to be elevated, indicating a need for vigilant care in newly diagnosed diabetics and hypertensives. Majority of the ACS occurred in the age group of 30 to 60 years, which is also deeply disturbing, as the age where the expectation of ACS has gone down in the recent past, and it is predicted to go down further in the future due to various lifestyle comorbidities. STEMI was the most common cardiac event. Among STEMI, AWMI was the most common.

SYNTAX score 1 was higher in patients with lateral wall myocardial infarction (LWMI) and was mildly significant. As the duration of alcohol use increased, the SYNTAX score 1 also increased, and this was statistically significant. The same holds good for systemic hypertension, and it was statistically significant. Another statistically significant observation was that the SYNTAX score 1 also increased, with clinical signs of left ventricular failure, as classified by Killip score.
Even though not statistically significant, the SYNTAX score 1 also increased with the duration of diabetes mellitus. SYNTAX score 1 was noticed to be maximal with LWMI.

Our study gives insight into the trends noticed in the ACS patient population that we have received in the recent past. The shocking occurrence of ACS in young and the risk factors that can be directly attributed to the pathology also need to be taken into consideration.

\section{Audio 1}

Audio file for this article is available at: https://doi. org/10.1055/s-0041-1736251.

Conflict of Interest

None declared.

\section{Reference}

1 Roffi M, Patrono C, Collet JP, et al; ESC Scientific Document Group. 2015 ESC Guidelines for the management of acute coronary syndromes in patients presenting without persistent ST-segment elevation: Task Force for the Management of Acute Coronary Syndromes in Patients Presenting without Persistent ST-Segment Elevation of the European Society of Cardiology (ESC). Eur Heart J 2016;37(03):267-315

2 Amsterdam EA, Wenger NK, Brindis RG, et al. 2014 AHA/ACC guideline for the management of patients with non-ST-elevation acute coronary syndromes: A report of the American College of Cardiology/American Heart Association task force on practice guidelines. J Am Coll Cardiol 2014;64(24):e139-e228

3 Steg PG, James SK, Atar D, et al; Task Force on the management of ST-segment elevation acute myocardial infarction of the European Society of Cardiology (ESC) ESC Guidelines for the management of acute myocardial infarction in patients presenting with ST-segment elevation. Eur Heart J 2012;33(20):2569-2619

4 Padley SPG, Roditi G, Nicol EDBSCI/BSCCT. Chest pain of recent onset: assessment and diagnosis (CG95). A step change in the requirement for cardiovascular CT. Clin Radiol 2017;72(09):751-753

5 Farooq V, Girasis C, Magro M, et al. The CABG SYNTAX Score - an angiographic tool to grade the complexity of coronary disease following coronary artery bypass graft surgery: from the SYNTAX Left Main Angiographic (SYNTAX-LE MANS) substudy. EuroIntervention 2013;8(11):1277-1285

6 Amsterdam EA, Wenger NK, Brindis RG, et al; ACC/AHA Task Force Members. 2014 AHA/ACC guideline for the management of patients with non-ST-elevation acute coronary syndromes: a report of the American College of Cardiology/American Heart Association Task Force on Practice Guidelines. Circulation 2014; 130(25):e344-e426

7 Prajapati J, Joshi H, Sahoo S, Virpariya K, Parmar M, Shah K. Agerelated differences of novel atherosclerotic risk factors and angiographic profile among gujarati acute coronary syndrome patients. J Clin Diagn Res 2015;9(06):OC05-OC09

8 Perelshtein Brezinov O, Klempfner R, Zekry SB, Goldenberg I, Kuperstein R. Prognostic value of ejection fraction in patients admitted with acute coronary syndrome: A real world study. Medicine (Baltimore) 2017;96(09):e6226

9 Björck L, Rosengren A, Wallentin L, Stenestrand U. Smoking in relation to ST-segment elevation acute myocardial infarction: findings from the Register of Information and Knowledge about Swedish Heart Intensive Care Admissions. Heart 2009;95(12): 1006-1011 
10 Katayama T, Iwasaki Y, Sakoda N, Yoshioka M. The etiology of 'smoker's paradox' in acute myocardial infarction with special emphasis on the association with inflammation. Int Heart J 2008; 49(01):13-24

11 Leong DP, Smyth A, Teo KK, et al; INTERHEART Investigators. Patterns of alcohol consumption and myocardial infarction risk: observations from 52 countries in the INTERHEART case-control study. Circulation 2014;130(05):390-398

12 Isezuo S, Subban V, Krishnamoorthy J, et al. Characteristics, treatment and one-year outcomes of patients with acute coronary syndrome in a tertiary hospital in India. Indian Heart J 2014; 66(02):156-163

13 Choudhary S. Association of syntax score with short-term outcomes among acute ST-elevation myocardial infarction patients undergoing primary PCI. Indian Heart J 2017;69(Suppl 1):S20-S23
14 Tanveer S, Banu S, Jabir NR, et al. Clinical and angiographic correlation of high-sensitivity C-reactive protein with acute ST elevation myocardial infarction. Exp Ther Med 2016;12(06):4089-4098

15 Dursun I. Comparison of Angiographic and Clinical Findings in Non-St Elevation Versus St Elevation Myocardial Infarction. Am J Cardiol 2018;121(08):e23

16 Kurmus O, Erkan AF, Ekici B, Aslan T, Eren M. Discordance of lowdensity lipoprotein cholesterol and non-high-density lipoprotein cholestrol and coronary artery disease severity. Arq Bras Cardiol 2020;114(03):469-475

17 Li Y, Li S, Ma Y, Li J, Lin M, Wan J. Relationship between nonhigh-density lipoprotein cholesterol/apolipoprotein A-I and monocyte/high-density lipoprotein cholesterol ratio and coronary heart disease. Coron Artery Dis 2020;31(07): 623-627 